\title{
ESTILOS DE APRENDIZAGEM NO ENSINO REMOTO: UM CASO DE ENGENHARIA DE PRODUÇÃO
}

Lucas AB de Oliveira-lucasambro@ufersa.edu.br

Universidade Federal Rural do Semiárido - UFERSA

Centro Multidisciplinar de Angicos, Departamento de Engenharias

Rua Gamaliel Martins Bezerra, 587. Alto da Alegria

59515000 - Angicos, RN-Brasil

LucianaTCMello-Luciana.mello@ufersa.edu.br

Universidade Federal Rural do Semiárido - UFERSA

Centro Multidisciplinar de Angicos, Departamento de Engenharias

Rua Gamaliel Martins Bezerra, 587. Alto da Alegria

59515000 - Angicos, RN-Brasil

Resumo: o objetivo deste artigo é identificar o estilo de aprendizagem do(a) discente de um curso de graduação presencial, no contexto do ensino remoto. Para isso, foi aplicada uma survey com discentes do curso de engenharia de produção, matriculados em disciplinas remotas. $O$ instrumento de pesquisa foi elaborado com base no modelo VAKR. Os resultados indicam uma predominância da "Escrita" e "Audição" como estilos de aprendizagem com os quais os(as) discentes mais se identificam. À medida que avançam nos semestres do curso, percebe-se "amadurecimento" nos estilos de aprendizagem dos(as) estudantes, por exemplo: há iniciantes que não se identificam com o estilo "Fala"; entre os(as) veteranos(as), entretanto, percebe-se uma maior identificação com esse estilo. Com base nessas informações, docentes tiveram informações para otimizar suas estratégias de ensino em disciplinas remotas.

Palavras-chave: Estilos de aprendizagem. Ensino remoto. Engenharia de produção. Estratégias para ensino.

\section{INTRODUÇÃO}

A pandemia provocada pelo corona vírus SARS-CoV-2, COVID-19 (WHO, 2020), trouxe várias implicações para o mundo e, no contexto da educação, causou, em primeiro momento, a suspensão das aulas e, em segundo momento, a "transição" das aulas presenciais para a modalidade remota ou de educação à distância (AZEVEDO, 2020; BRASIL, 2020; MELO, 2020).

Um dos desafios relacionados aos efeitos dessa transição relaciona-se ao processo de ensino-aprendizagem do corpo discente, que sai de um contexto conhecido (ensino presencial) e passa a aprender e interagir em um contexto remoto. No contexto remoto os(as) discentes têm maior carga de responsabilidade no processo de aprendizagem e, além disso, tem que aprender e implementar/executar, simultaneamente, ações para as quais não estavam habituados (HODGES et al., 2020). Estes elementos demandam do(a) discente um maior conhecimento sobre seus pontos fortes e limitações no processo e estilo de aprendizagem.

Destarte, este trabalho tem como objetivo identificar o estilo de aprendizagem discente de um grupo de discentes matriculados em disciplinas remotas um curso de graduação presencial. 
Este trabalho mostra-se relevante e oportuno por perceber que o diagnóstico sobre o estilo de aprendizagem do(a) discente pode auxiliar na transição e adaptação para o ensino remoto, indicando quais são as estratégias mais indicadas para seu perfil. Além disso, na perspectiva do(a) docente, conhecer o perfil de aprendizagem da turma pode auxiliá-lo(a) no planejamento do componente curricular, priorizando ações que sejam convergentes. Outrossim, conhecer os estilos de aprendizagem pode contribuir para a compreensão dos processos de aprendizagem, inclusive, nos ambientes virtuais da educação à distância e remotos (SILVA et al., 2019).

Para tanto, este artigo está estruturado em seis seções. Essa seção, de caráter introdutório, traz a contextualização do tema com problema e objetivo. A seção dois e três trazem uma breve descrição dos estilos de aprendizagem e alguns modelos discutidos na literatura. A seção quatro fala sobre os procedimentos da pesquisa. A seção cinco mostra os resultados e, por fim, a seção seis aborda as conclusões.

\section{ESTILOS DE APRENDIZAGEM}

São os estilos pelos quais os indivíduos preferem receber e processar as informações (SILVA et al., 2019). Apesar dos relatos, reflexões e alertas que Kirschner (2017) faz sobre as pesquisas sobre os estilos de aprendizagem, Hsu (2017) relata estudos que confirmam modelos que tratam deste assunto e destaca que docentes devem considerar as diferentes demandas dos(as) discentes e definir estratégias para atender aos diversos estilos de aprendizagem. Truong (2016) corrobora apontando que cada discente tem a sua forma preferida de aprender.

Assim, apesar das críticas e limitações relacionadas à forma como as pesquisas são feitas, acredita-se que a compreensão sobre os estilos de aprendizagem pode auxiliar na prática docente, de ensino-aprendizagem e pode auxiliar o(a) docente no processo de elaboração das estratégias didáticas-pedagógicas, instruções e materiais para os diferentes estilos de aprendizagem.

Negreiros, Silva e Lima (2017) e Truong (2016) apontam que os estilos de aprendizagem são compostos por elementos (cognitivos, afetivos e fisiológicos) que indicam o estilo como o(a) discente processa o aprendizado em torno de um tema. Além disso, Truong (idem) destaca que há pesquisadores e autores que apontam não para "estilos", mas para táticas de aprendizagem e, neste caso, elas se adaptam conforme a situação. Portanto, a identificação dos estilos de aprendizagem pode ser útil para auxiliar, tanto docente quanto discente, na transição "presencial-remoto" provocada pela pandemia da COVID-19.

\section{MODELOS DE ESTILOS DE APRENDIZAGEM}

Schmitt e Domingues (2016) e Nascimento et al. (2017), em seus respectivos estudos, destacam vários modelos como: KOLB, VARK, Honey-Alonso, Felder e Silverman, Dunn e Dunn, dentre outros. Cada um tem especificidades, mas todos propõe uma classificação baseado em ações e estratégias de aprendizado e comportamento. O modelo VARK (Visual, Aural, Read/write, e Kinesthetic - Visual, auditiva, leitura/escrita e cinestésicas), proposto por Fleming e Mills (1992), está mais associados aos sentidos humanos, sensorial, perceptivo e, também, ao desenvolvimento pessoal (SCHMITT; DOMINGUES, 2016) e, portanto é o utilizado por este trabalho. 
O estilo ou a classificação visual (V) indica preferência por informações visuais em formas de mapas, diagramas, fluxogramas, dentre outros elementos, que representam palavras. A classificação auditiva (A) sugere melhor aprendizado com palestras, discussões/debates, rádio, dentre outros dispositivos e ações que inclua a comunicação verbal, incluindo falar em voz alta consigo mesmo(a). O estilo de leitura/escrita (R) compreende a preferências por palavras, indicando prazer na leitura e escrita. A classificação cinestésico $(\mathrm{K})$ trata da experimentação (prática ou simulada) em torno de um tema.

Para medir essa classificação, existe um inventário VARK construído a partir de situações concretas e reais, considerando a multimodalidade, que considerada todos os quatros estilos de aprendizagem do modelo, que são duas: "VARK tipo Um" e "VARK tipo dois". Quando um(a) discente não tem um destaque muito grande em uma das classificações do VARK, o(a) mesmo(a) podem entrar em uma das duas categorias.

Na primeira, o respondente pode usar a(s) classificação(ções) da forma mais conveniente no momento; no VARK tipo dois, o indivíduo busca compreensão profunda e sob várias perspectivas sobre o assunto em estudo, caracterizando-o como o resultado mais comum (LEITE; SVINICKI; SHI, 2010). Para além desses dois tipos, o modelo VARK possui um conjunto de 25 preferências, que retratam desde preferências únicas de classificação (divididas em intensidades), até preferências bi e tri-modais, ou seja, duas ou três predominâncias nas classificações do VARK.

O instrumento VARK (2020)é composto por 16 questões sobre diferentes situações, assim como as alternativas. São situações "problema" onde as o(a) respondente escolhe uma ou mais alternativa que ela gostaria de usar. Considerando a frequência de escolha das alternativas, que estão relacionadas a uma das classificações VARK, é feita contagem de preferência e, em seguida, tem-se o resultado da classificação.

\section{MÉTODO DE PESQUISA}

Com a finalidade de identificar o estilo de aprendizagem de um grupo de discentes de um curso de graduação presencial em transição para remoto, este trabalho trata-se de uma pesquisa quantitativa utilizando o método survey. A pesquisa quantitativa faz uso de variáveis para serem mensuradas por meio de evidências, buscando uma relação causal, sugerindo replicação e generalização (MARTINS, 2012) e o método survey pesquisa fenômenos com variáveis já definidas, também para obter uma relação causal (MIGUEL; HO, 2012).

A pesquisa iniciou com a elaboração do instrumento de pesquisa dividido em duas partes. A primeira parte teve como objetivo traçar um breve perfil sobre os discentes respondentes. Para isso, buscou-se saber sobre o momento do curso em que estes se encontravam, se no $1^{\circ}$ ciclo (Bacharel em Ciência e Tecnologia) ou no $2^{\circ}$ Ciclo (Engenharia de Produção), período atual no curso, idade e disciplinas com pretensão de matrícula no "semestre remoto".

A segunda parte do questionário buscou identificar os estilos de aprendizagem por meio de afirmações e, para isso, quatro opções de respostas estavam disponíveis "completamente verdadeiro", "parcialmente verdadeiro", "completamente falso", e "ainda não sei". As afirmações foram desenvolvidas considerando cinco variáveis de estilos de aprendizagem (1) leitura, (2) escrita, (3) fala, (4) audição e (5) visualização, tomando como base a metodologia VARK de Fleming e Mills (1992). Para cada estilo foram desenvolvidas cinco afirmações, totalizando 25. É importante ressaltar que foram realizadas adaptações a partir do instrumento VARK, como, por exemplo, no estilo leitura/escrita (R), que foi considerado de forma 
separada, e também na experimentação/prática $(\mathrm{K})$, que foi excluído considerando que no ensino remoto, nessa primeira experiência, não estaria presente. O Quadro 1 traz as 25 afirmações agrupadas por estilo de aprendizagem (Ler - Escrever - Falar - Visualizar - Ouvir).

O questionário, em formulário on-line, foi divulgado por meios digitais aos(as) discentes do curso de graduação, em um momento posterior da decisão de iniciar um "semestre remoto", isso iria propiciar aos docentes conhecerem os estilos dos discentes e, consequentemente, planejar melhor as aulas remotas, e também aos discentes, sugestões antecipadas de estudo para lidarem melhor com esse momento. No curso presencial (ministrado remotamente, devido a pandemia), na qual a pesquisa foi aplicada, havia 85 matrículas ativas no momento do envio do formulário e, obteve-se um total de 52 respondentes.

Os resultados foram analisados de duas formas. A primeira análise esteve relacionada ao estilo do grupo como um todo, e para isso foram considerados os gráficos obtidos por meio do próprio formulário on-line. Já a segunda parte da análise buscou identificar o estilo de aprendizagem de cada discente respondente de forma individual. Com isso, foi possível um retorno particular para cada um(a) deles, informando seu estilo e algumas sugestões/recomendações.

Quadro 1 - Instrumento de avaliação

\begin{tabular}{|c|c|c|c|c|}
\hline LER & ESCREVER & FALAR & VISUALIZAR & OUVIR \\
\hline $\begin{array}{l}\text { 1. Quando tenho } \\
\text { tempo livre gosto } \\
\text { de ler }\end{array}$ & $\begin{array}{l}\text { 6. É costumeiro } \\
\text { estudar o conteúdo } \\
\text { da prova fazendo } \\
\text { resumos e resenhas }\end{array}$ & $\begin{array}{l}\text { 11. Durante um } \\
\text { congresso, prefiro } \\
\text { participar de } \\
\text { discussões do que } \\
\text { ouvir as palestras }\end{array}$ & $\begin{array}{l}\text { 16. Para aprender } \\
\text { uma ferramenta } \\
\text { nova, uso tutoriais } \\
\text { em vídeo }\end{array}$ & $\begin{array}{l}\text { 21. Seria } \\
\text { proveitoso pode } \\
\text { ouvir as gravações } \\
\text { das aulas } \\
\text { novamente, antes } \\
\text { das provas }\end{array}$ \\
\hline $\begin{array}{l}\text { 2. A leitura do } \\
\text { manual é } \\
\text { obrigatória para } \\
\text { mim, quando } \\
\text { compro um novo } \\
\text { item tecnológico }\end{array}$ & $\begin{array}{l}\text { 7. Ao resolver um } \\
\text { problema da aula } \\
\text { com o professor, } \\
\text { prefiro escrever } \\
\text { um email do que } \\
\text { falar pessoalmente }\end{array}$ & $\begin{array}{l}\text { 12. Ao me } \\
\text { preparar para uma } \\
\text { apresentação de } \\
\text { trabalho, treino as } \\
\text { apresentações } \\
\text { falando em voz } \\
\text { alta }\end{array}$ & $\begin{array}{l}\text { 17. Ao assistir uma } \\
\text { palestra, só a } \\
\text { apresentação em } \\
\text { slides é suficiente } \\
\text { para meu } \\
\text { entendimento }\end{array}$ & $\begin{array}{l}\text { 22. Ao buscar } \\
\text { notícias da } \\
\text { atualidade, busco } \\
\text { vídeos na internet }\end{array}$ \\
\hline $\begin{array}{l}\text { 3. Quando um } \\
\text { professor expõe os } \\
\text { slides da aula, eu } \\
\text { preciso ler o que } \\
\text { está escrito, antes } \\
\text { ou durante sua fala }\end{array}$ & $\begin{array}{l}\text { 8. Antes de uma } \\
\text { prova de cálculo, } \\
\text { preciso refazer os } \\
\text { exercícios, para } \\
\text { fixar o conteúdo }\end{array}$ & $\begin{array}{l}\text { 13. Quando leio } \\
\text { um livro, ou } \\
\text { estudo, faço isso } \\
\text { em voz alta }\end{array}$ & $\begin{array}{l}\text { 18. Durante uma } \\
\text { prova, eu lembro } \\
\text { do conteúdo, ao } \\
\text { pensar nos slides } \\
\text { da aula }\end{array}$ & $\begin{array}{l}\text { 23. Acho os áudio } \\
\text { livros mais } \\
\text { interessantes que } \\
\text { os livros em si }\end{array}$ \\
\hline $\begin{array}{l}\text { 4. Para explicar } \\
\text { sobre o meu curso } \\
\text { a alguém, busco } \\
\text { textos com } \\
\text { definições já } \\
\text { prontos }\end{array}$ & $\begin{array}{l}\text { 9. Para fixar o } \\
\text { conteúdo de uma } \\
\text { leitura, faço } \\
\text { anotações }\end{array}$ & $\begin{array}{l}\text { 14. Para meu } \\
\text { melhor } \\
\text { entendimento, } \\
\text { costumo tirar } \\
\text { dúvidas durante as } \\
\text { apresentações }\end{array}$ & $\begin{array}{l}\text { 19. Em aulas de } \\
\text { cálculo, é } \\
\text { suficiente ver/ler } \\
\text { os exercícios } \\
\text { resolvidos para } \\
\text { aprender }\end{array}$ & $\begin{array}{l}\text { 24. Escuto } \\
\text { podcasts } \\
\text { frequentemente } \\
\text { para ter notícias e } \\
\text { informações atuais }\end{array}$ \\
\hline $\begin{array}{l}\text { 5. É muito } \\
\text { importante para } \\
\text { meu entendimento, } \\
\text { fazer leitura de } \\
\text { material antes da } \\
\text { aula }\end{array}$ & $\begin{array}{l}\text { 10. Prefiro } \\
\text { responder } \\
\text { questionários } \\
\text { subjetivos do que } \\
\text { de múltipla } \\
\text { escolha }\end{array}$ & $\begin{array}{l}\text { 15. Ao explicar } \\
\text { como utilizar uma } \\
\text { nova ferramenta, } \\
\text { prefiro gravar um } \\
\text { áudio do que } \\
\text { escrever as } \\
\text { instruções }\end{array}$ & $\begin{array}{l}\text { 20. Ao visitar um } \\
\text { website de } \\
\text { notícias, vou } \\
\text { imediatamente } \\
\text { para as imagens, } \\
\text { antes de fazer a } \\
\text { leitura }\end{array}$ & $\begin{array}{l}\text { 25. Aprendo muito } \\
\text { quando outras } \\
\text { pessoas fazem } \\
\text { perguntas, e escuto } \\
\text { as respostas }\end{array}$ \\
\hline
\end{tabular}

Fonte: os autores (2020). 
(C) COBENGE 2020

"Os desafios para formar hoje o engenheiro do amanhã"

\section{RESULTADOS}

Dos 85 discentes matriculados em disciplinas ofertadas pelo curso de graduação em Engenharia de Produção, 50 responderam ao questionário adaptado. A média de idade dos(as) respondentes é de 24,5 anos (Desvio padrão $=2,99$ ); apenas 5 discentes eram do $5^{\circ} \mathrm{e}$ $6^{\circ}$ semestre, os demais eram do $7^{\circ}$ semestre em diante, ou seja, já do segundo ciclo, conforme ilustra Figura 01. A partir das respostas, foi possível identificar qual(ais) estilo(s) de aprendizagem é/são frequente(s) nas atividades de estudo dos(as) discentes.

Figura 01 - Curso dos alunos matriculados e período cursado.

Curso atual (CeT e EP)

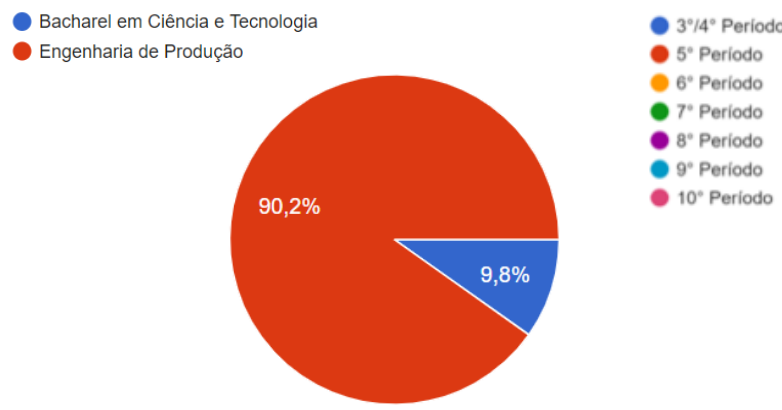

Período cursado

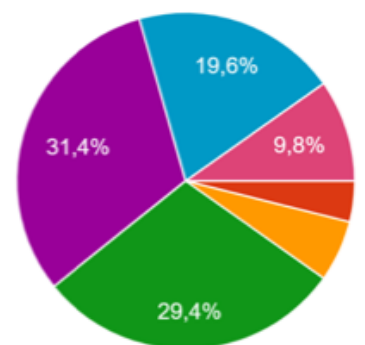

Fonte: dados da pesquisa (2020). CeT = Curso de Ciência e Tecnologia; EP = Curso de Engenharia de Produção.

Em relação ao perfil estilo VARK de tal grupo de discentes, observou-se que há classificação multimodalidade. Um resultado "completamente verdadeiro" sugere predominância e facilidade na aprendizagem por meio desse estilo em análise. É possível que seja o estilo mais utilizado pelo respondente. Um resultado "parcialmente verdadeiro" sugere que, apesar de não ser o estilo de aprendizagem predominante, o(a) respondente demonstra grande aceitação e adaptação a ele. Um resultado "completamente falso" sugere que o estilo em análise não tem grande contribuição para seu processo de aprendizagem. Destaca-se que esse não é um resultado definitivo: se desejar, é possível utilizar estratégias de estudo que permitam abertura para desenvolver e amadurecer esse estilo, que pode vir a se destacar. Um resultado "ainda não sei" indica que, no momento da pesquisa, ainda não há aspectos definidos que destaquem um dos estilos do estilo de aprendizagem. Essa informação não deve gerar apreensões no(a) discente. O processo de aprendizagem é complexo e existe a possibilidade de ainda não ter tido contato direto com todos os estilos e, portanto, não os reconhecer prontamente.

Em geral, dos 100\% de respostas, observou-se que a identificação com os estilos de aprendizagem foram: 32\% Escrita, 26\% Fala, 20\% Audição, 12\% Visualização e 10\% Leitura. Em segunda análise, percebe-se que o estilo de aprendizagem dos discentes de forma geral (Figura 02), na amostra do estudo, $76 \%$ dos respondentes se identificaram com o estilo Escrita. 


\section{Evento On-line}

Figura 02 - Estilos de aprendizagem discentes (todos períodos).

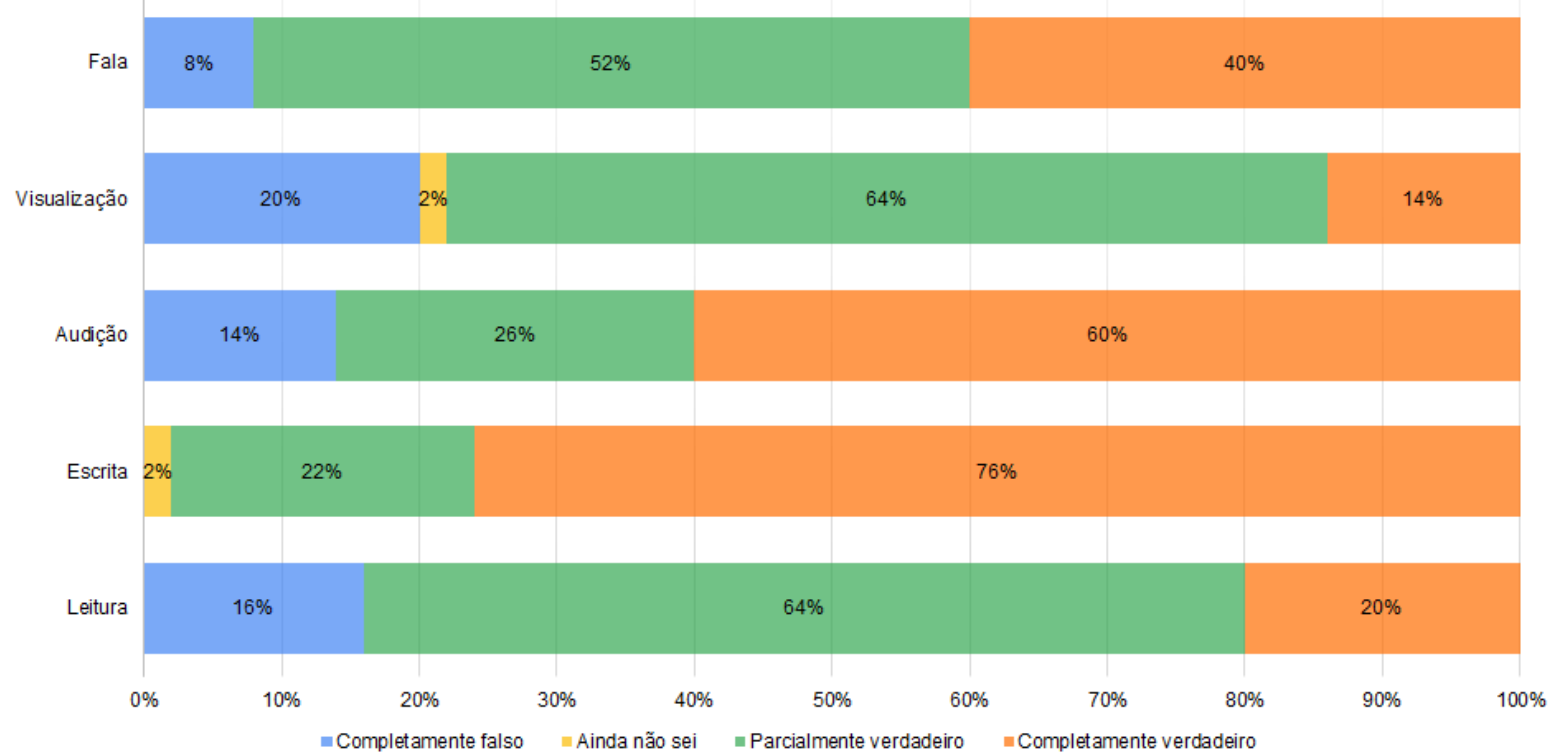

Fonte: dados da pesquisa (2020).

Além disso, no estilo Escrita, é importante observar que não houve resposta na escala "completamente falso", ou seja, não há dúvidas de que está modalidade, apesar da incerteza de um respondente, é a mais bem aceita entre os discentes que participaram da pesquisa. Visualização e leitura, apesar da não predominância, têm respostas mais frequentes com o nível de concordância "parcialmente verdadeiro": 64\% ambas.

Figura 03 - Análise dos estilos de aprendizagem dos discentes $5^{\circ}, 6^{\circ}$ e $7^{\circ}$ período.

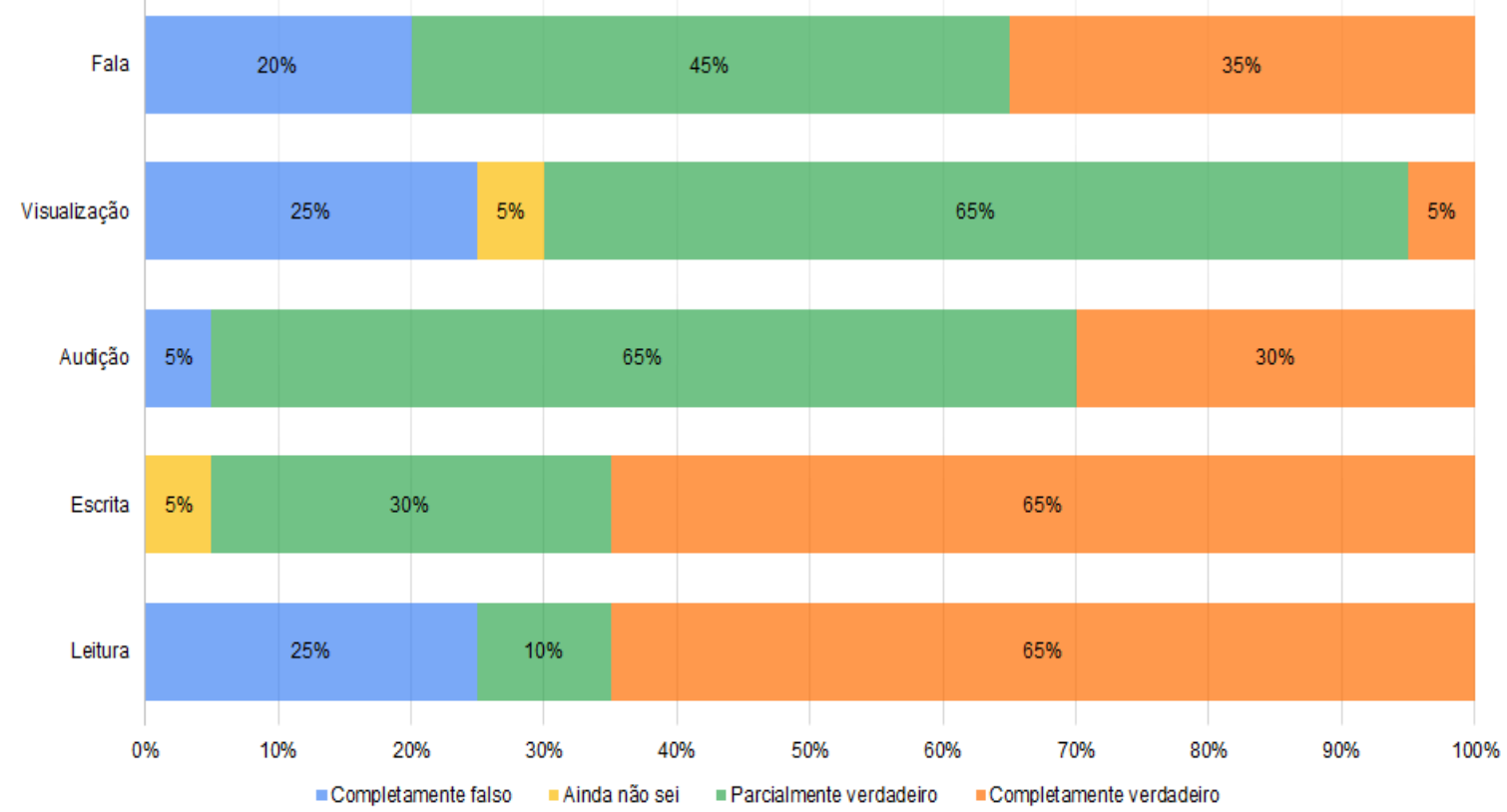

Fonte: dados da pesquisa (2020).

Observando as Figuras 03 e 04, é interessante perceber que há uma tendência de que, de acordo com o período do curso, há um percentual menor na escala "Completamente falso". 
Por exemplo, no estilo "Fala" 20\% dos(as) discentes do $5^{\circ}, 6^{\circ}$ e $7^{\circ}$ período tiveram uma classificação neste estilo; enquanto que entre aqueles(as) do $8^{\circ}, 9^{\circ}$ e $10^{\circ}$ período, este percentual foi zero. Essa mesma tendência de redução acontece nos estilos "Visualização", "Audição" e "Leitura".

Outra percepção interessante é que, no estilo "Audição" e "Escrita" houve um aumento das classificações em "Completamente verdadeiro", indicando crescimento de preferência por tais estilos conforme avançam no curso. Por outro lado, no estilo "Leitura" percebe-se que a escala "Completamente verdadeira" era maior entre discentes do $5^{\circ}, 6^{\circ}$ e $7^{\circ}$ período, o que pode ter relação com o fato de que as disciplinas com maior carga teórica estão alocadas nestes períodos.

Figura 04 - Análise dos estilos de aprendizagem dos discentes $8^{\circ}, 9^{\circ}$ e $10^{\circ}$ período.

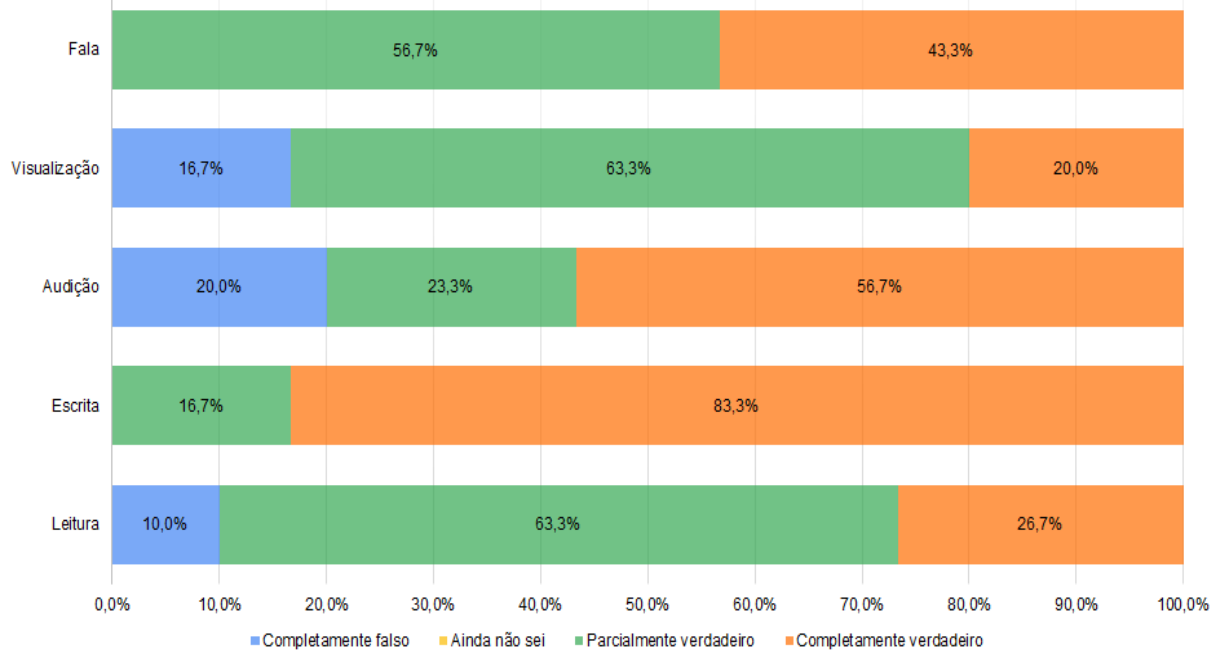

Fonte: dados da pesquisa (2020).

Acredita-se que estes resultados são condizentes com o perfil do curso de engenharia de produção. Para cada estilo de aprendizagem foram desenvolvidas dicas de aprendizagem, considerando a utilização para o ensino remoto.

Para o estilo com ênfase na escrita, entende-se que algumas opções para aprender melhor são ensinando, demonstrando e praticando/fazendo. Assim, aos discentes sugere-se o desenvolvimento de textos-resumos após receber o conteúdo que pode ser pela leitura de algo, ou visualização e escuta de uma aula ou palestra. Ao escrever o conteúdo "recebido", o discente está organizando as informações ao seu estilo, memorizando e, consequentemente, aprendendo. Aos docentes sugere-se que nas aulas, solicite atividades avaliativas como os artigos, as resenhas críticas e os próprios resumos.

Para o estilo de aprendizado com ênfase na fala, é mais comum que se aprenda ensinando, discutindo pontos de vista e demonstrando. $\mathrm{O}$ tom da fala funciona como uma ferramenta de memorização. Aos discentes, sugere-se também buscar tirar dúvidas no ambiente de sala de aula em voz alta, mesmo que sejam repetições do que já foi dito, por que facilitará a absorção. Aos docentes sugere-se passar atividades que proporcione ao(a) estudante a oportunidade de interação, na qual é possível expor seu ponto de vista e exercitar o aprendizado por meio da exposição nas falas.

Para quem aprende melhor por meio da audição, sugere-se assistir aulas expositivas e palestras. Em sala de aula, a exposição em formato de apresentação é uma boa opção para os discentes e docentes, assim como também grupos de discussão, nos quais, além do professor, 
outros também compartilham seus pontos de vistas por meio da fala. No momento atual, ferramentas de explicações/leituras por meio do áudio, como os podcasts, também são boas opções para os discentes. Aos docentes, recomenda-se também o cuidado com a fala (aspectos como clareza, espaçamento e articulação) para que a mensagem seja repassada ao discente de forma mais fluida e assertiva possível.

Para estilo com ênfase na visualização, mídias visuais como as aulas expositivas com imagens, gráficos, tabelas, quadros e esquemas, são opções satisfatórias aos discentes, se utilizadas pelos docentes. As imagens auxiliam na retenção do conteúdo na memória, levando uma ideia lógica e facilitando o entendimento do conceito.

O estilo de aprendizagem da leitura é o mais presente no meio acadêmico diante da frequência de textos (livros e artigos acadêmicos) utilizados. Nesse estilo, docentes e discentes buscam materiais já escritos para adquirir informações e conhecimento, mesmo que em formato digital. Nesse estilo, a interpretação pessoal e crítica do leitor/discente é o que vai produzir conhecimento para si. Aos discentes adeptos desse estilo, sugere-se cuidado na busca e seleção dos materiais, principalmente nas mídias digitais, para não tomar como verdadeiras informações sem o devido rigor científico.

Além disso, para docentes, sugere-se algumas estratégias: para estilo "Falar", sugerir seminários com duração proporcional ao semestre (quanto mais avançado, maior o tempo de apresentação); para o estilo "Visualização", pode-se utilizar slides, imagens vídeos, documentários atrativos sobre o tema da aula; para o estilo "Audição", pode-se criar podcast curtos para introduzir algum tema ou apresentar algum caso interessante; para o estilo "Escrita", pode-se estimular a escrita de argumentos em forma de postagem nos feeds em redes sociais e criar um perfil/grupo específico para esta finalidade; para o estilo "Leitura", pode-se indicar, ao invés de capítulos completos, seções específicas.

\section{CONCLUSÕES}

Considerando o objetivo deste trabalho, "identificar o estilo de aprendizagem discente de um grupo de discentes de um curso de graduação presencial em transição para remoto", considera-se que o mesmo foi alcançado e que o estilo de aprendizagem com o qual os discentes mais se identificam, no curso avaliado é a Escrita, e o que menos se identificam é a Leitura. Essa característica traz alguns desafios no contexto do ensino remoto, pois a carga de leitura tende a ser maior do que no ensino presencial, pois algumas informações passadas vocalmente agora são apresentadas em formas de texto. Além disso, há aumento da demanda de leitura do material de aula.

Independente da identificação dos estilos de aprendizagem pelos discentes é importante alertar que a aprendizagem é um processo e que é possível desenvolver habilidades e competências para aprimorar o ensino-aprendizagem de cada estilo. Nesse sentido percebese a necessidade de adaptações do ensino presencial para o ensino remoto, principalmente no estilo Leitura, que contrariando a identificação dos discentes, é o mais utilizado nos ambientes acadêmicos pelos docentes.

\section{REFERÊNCIAS}

AZEVEDO, Margarida. Universidades federais planejam aulas online após 4 meses. Universidades federais planejam aulas online após 4 meses, [s. l.], 19 jul. 2020 
Disponível em: https://jc.ne10.uol.com.br/colunas/enem-e-educacao/2020/07/11955443universidades-federais-planejam-aulas-online-apos-4-meses.html. Acesso em: 7 ago. 2020.

BRASIL, Ministério da Educação. Corona Vírus - Monitoramento nas Instituições de Ensino. [s. l.], 2020. Disponível em: http://portal.mec.gov.br/coronavirus/. Acesso em: 7 ago. 2020.

FLEMING, Neil D.; MILLS, Colleen. Not Another Inventory, Rather a Catalyst for Reflection. To Improve the Academy, [S. l.], v. 11, n. 1, p. 137-155, 1992. Disponível em: https://doi.org/10.1002/j.2334-4822.1992.tb00213.x

HODGES, Charles et al. As diferenças entre o aprendizado online e o ensino remoto de emergência. Revista da Escola, Professor, Educação e Tecnologia, [S. l.], v. 2, 2020. Disponível em: http://escribo.com/revista/index.php/escola/article/view/17. Acesso em: 7 ago. 2020.

HSU, Ting-Chia. Learning English with Augmented Reality: Do learning styles matter? Computers \& Education, [S. l.], v. 106, p. 137-149, 2017. Disponível em: https://doi.org/10.1016/j.compedu.2016.12.007

KIRSCHNER, Paul A. Stop propagating the learning styles myth. Computers \& Education, [S. l.], v. 106, p. 166-171, 2017. Disponível em: https://doi.org/10.1016/j.compedu.2016.12.006

LEITE, Walter L.; SVINICKI, Marilla; SHI, Yuying. Attempted Validation of the Scores of the VARK: Learning Styles Inventory With Multitrait-Multimethod Confirmatory Factor Analysis Models. Educational and Psychological Measurement, [S. l.], v. 70, n. 2, p. 323-339, 2010. Disponível em: https://doi.org/10.1177/0013164409344507

MARTINS, R. A. Abordagens quantitativa e qualitativa. In: CAUCHICK MIGUEL, Paulo Augusto et al. (org.). Metodologia de pesquisa em engenharia de produção e gestão de operações. 2. ed. Rio de Janeiro: Elsevier, 2012. p. 47-56. E-book.

MELO, Karine. MEC autoriza aulas online no ensino superior até dezembro. MEC autoriza aulas online no ensino superior até dezembro, Brasília, 17 jun. 2020 Disponível em: https://agenciabrasil.ebc.com.br/educacao/noticia/2020-06/mec-autoriza-aulas-line-noensino-superior-ate-dezembro. Acesso em: 7 ago. 2020.

MIGUEL, P. A. C.; HO, L. L. Levantamento tipo survey. In: MIGUEL, Paulo Augusto Cauckick et al. (org.). Metodologia de pesquisa em engenharia de produção e gestão de operações. 2. ed. Rio de Janeiro: Elsevier, 2012. p. 47-56. E-book.

NASCIMENTO, Priscilla do et al. Recomendação de Objetos de Aprendizagem baseada em Modelos de Estilos de Aprendizagem: Uma Revisão Sistemática da Literatura.

Brazilian Symposium on Computers in Education (Simpósio Brasileiro de Informática na Educação - SBIE), [S. l.], v. 28, n. 1, p. 213, 2017. Disponível em:

https://doi.org/10.5753/cbie.sbie.2017.213

NEGREIROS, Fauston; SILVA, Ellery Henrique Barros da; LIMA, Jennifer Alves. 
ESTILOS DE APRENDIZAGEM NO ENSINO SUPERIOR: um estudo com universitários ribeirinhos do Piauí. Revista Educação e Emancipação, [S. l.], v. 0, n. 0, p. 277-302, 2017. Disponível em: https://doi.org/10.18764/2358-4319.v9n3p277-302

SCHMITT, Camila da Silva; DOMINGUES, Maria José Carvalho de Souza. Learning styles: a comparative study. Avaliação: Revista da Avaliação da Educação Superior (Campinas), [S. l.], v. 21, n. 2, p. 361-386, 2016. Disponível em: https://doi.org/10.1590/S1414-40772016000200004

SILVA, Fabiana Adão et al. O Modelo EaD e Estilos de Aprendizagem: Um Estudo de Caso no Colégio Pedro II. EaD em Foco, [S. l.], v. 9, n. 1, 2019.

TRUONG, Huong May. Integrating learning styles and adaptive e-learning system: Current developments, problems and opportunities. Computers in Human Behavior, [S. l.], v. 55, p. 1185-1193, 2016. Disponível em: https://doi.org/10.1016/j.chb.2015.02.014

VARK. VARK - A Guide to Learning Styles. [s. l.], 2020. Disponível em: https://varklearn.com. Acesso em: 8 ago. 2020.

WHO, World Health Organization. Naming the coronavirus disease (COVID-19) and the virus that causes it. [s. l.], 2020. Disponível em:

https://www.who.int/emergencies/diseases/novel-coronavirus-2019/technicalguidance/naming-the-coronavirus-disease-(covid-2019)-and-the-virus-that-causes-it. Acesso em: 4 ago. 2020.

\title{
LEARNING STYLES IN REMOTE TEACHING: A CASE IN PRODUCTION ENGINEERING
}

\begin{abstract}
: the aim of this paper is to identify the student learning style of a group of students from a face-to-face undergraduate course in transition to remote. For this, a survey was applied with students of production engineering course, enrolled in remote disciplines. The research instrument was designed based on the VAKR model. The results indicate a predominance of "Writing" and "Hearing" as learning styles with which the students most identified. As they progress in the semesters of the course, "maturity" was noticed in the students' learning styles, for example: there are novice students who do not identify with the "Speech" style; among veteran students, however, a greater identification with this style is perceived. Based on this information, professors had information to optimize their teaching strategies in remote subjects.
\end{abstract}

Keywords: Learning styles. Remote teaching. Production engineering. Teaching strategies. 